\title{
Agrobacterium-mediated genetic transformation of Miscanthus sinensis
}

\author{
Ok-Jin Hwang $\cdot$ Mi-Ae Cho $\cdot$ Yun-Jeong Han • \\ Yong-Min Kim · Soo-Hyun Lim • Do-Soon Kim • \\ Ildoo Hwang · Jeong-Il Kim
}

Received: 28 August 2013/ Accepted: 17 December 2013/Published online: 27 December 2013

(C) The Author(s) 2013. This article is published with open access at Springerlink.com

\begin{abstract}
Miscanthus species are tall perennial rhizomatous grasses with $\mathrm{C} 4$ photosynthesis originating from East Asia, and they are considered as important bioenergy crops for biomass production. In this study, Agrobacterium-mediated transformation system for $M$. sinensis was developed using embryogenic calli derived from mature seeds. In order to establish a stable system, optimum conditions to obtain highly regenerable and transformation-competent embryogenic calli were investigated, and embryogenic calli were efficiently induced with callus induction medium containing $3 \mathrm{mg} \mathrm{L}^{-1}$ 2,4-dichlorophenoxyacetic acid and $25 \mathrm{mM}$ L-proline, at $\mathrm{pH}$ 5.7 with an induction temperature of $28{ }^{\circ} \mathrm{C}$. In addition, the embryogenic callus induction and regeneration potentials were compared between seven $M$. sinensis germplasms collected from several sites in Korea, which revealed that the germplasm SNU-M-045 had superior embryogenic callus induction and regeneration potentials. With this germplasm,
\end{abstract}

Electronic supplementary material The online version of this article (doi:10.1007/s11240-013-0419-7) contains supplementary material, which is available to authorized users.

O.-J. Hwang · M.-A. Cho · Y.-J. Han · Y.-M. Kim ·

J.-I. Kim $(\square)$

Department of Biotechnology and Kumho Life Science

Laboratory, Chonnam National University, Gwangju 500-757,

Korea

e-mail: kimji@chonnam.ac.kr

S.-H. Lim · D.-S. Kim

Department of Plant Science, Research Institute for Agriculture and Life Sciences, College of Agriculture and Life Sciences,

Seoul National University, Seoul 151-921, Korea

I. Hwang

Department of Life Sciences and Biotechnology Research

Center, Pohang University of Science and Technology,

Pohang 790-784, Korea the genetic transformation of $M$. sinensis was performed using Agrobacterium tumefaciens EHA105 carrying pCAMBIA1300 with a green fluorescence protein gene as a reporter. After putative transgenic plants were obtained, the genomic integration of transgenes was confirmed by genomic PCR, transgene expression was validated by Northern blot analysis, and the number of transgene integration was confirmed by DNA gel blot analysis. Furthermore, the Agrobacteriummediated transformation of $M$. sinensis was also performed with pCAMBIA3301 which contains an herbicide resistance gene $(B A R)$, and we obtained transgenic $M$. sinensis plants whose herbicide resistance was confirmed by spraying with BASTA $^{\circledR}$. Therefore, we have established a stable Agrobacterium-mediated transformation system for $M$. sinensis, and also successfully produced herbicide-resistant Miscanthus plants by introducing $B A R$ gene via the established method.

Keywords Bioenergy crop - Embryogenic callus . Germplasm · Herbicide resistance $\cdot$ L-Proline

$\begin{array}{ll}\text { Abbreviations } \\ \text { BA } & \text { 6-Benzyl-adenine } \\ B A R & \text { A phosphinotricin acetyltransferase gene } \\ \text { bialaphos } & \text { Phosphinotricyl-alanyl-alanine } \\ \text { CIM } & \text { Callus induction medium } \\ \text { 2,4-D } & \text { 2,4-Dichlorophenoxyacetic acid } \\ e g f p & \text { Enhanced green fluorescence protein gene } \\ H Y G & \text { Hygromycin phosphotransferase II gene } \\ \text { PPT } & \text { Phosphinotricin }\end{array}$

\section{Introduction}

The production of biofuel from plant carbohydrates depends on the solar energy stored in plant biomass in the 
form of soluble sugars, starch and structural polysaccharides through photosynthesis (Gomez et al. 2008; Zhu et al. 2008). So far, bioethanol has mainly been produced from soluble sugars and starch, since they are more easily processed into biofuel than structural lignocellulose polysaccharides (Naik et al. 2010). However, this type of production appears unsustainable because of the potential competition with food and feed production. Therefore, there is extensive interest in lignocellulosic ethanol, because lignocellulosic biomass is an abundant, domestic, renewable source that can be converted to liquid transportation fuels (Yuan et al. 2008; Carroll and Somerville 2009; Balat 2011; Engler and Jakob 2013). Lignocellulosic feedstock for biofuel production is mostly $\mathrm{C} 4$ grasses that are characterized by high productivity and resource use efficiency, which includes Miscanthus species (van der Weijde et al. 2013).

Miscanthus species are tall perennial rhizomatous grasses with $\mathrm{C} 4$ photosynthesis, which typically reach heights of $\sim 4 \mathrm{~m}$ and tend to give high biomass yields annually (Heaton et al. 2008, 2010). Although Miscanthus is a genus comprising more than 20 species originating East-Asia, the triploid hybrid Miscanthus $\times$ giganteus $(2 \mathrm{n}=3 x=57)$ between the diploid M. sinensis $(2 \mathrm{n}=2 x=38)$ and the tetraploid M. sacchariflorus ( $2 \mathrm{n}=4 x=76$ ) is currently the species in the genus that is commercially grown (Lewandowski et al. 2000, 2003; Zub and Brancourt-Hulmel 2010). However, since this hybrid is sterile and lacks genetic variation, methods that can broaden the genetic base of the germplasm are necessary to advance Miscanthus species for further biotechnological applications. To broaden the genetic variation, attempts can be made to resynthesize this interspecific hybrid by making new crosses between its parental species (i.e., M. sinensis and $M$. sacchariflorus) and by searching for more natural hybrids. However, breeding goals of these approaches are difficult to meet if the end products of the breeding process are sterile. One way to address this problem is to focus on breeding efforts for the development of seed-propagated varieties in genetically stable and fertile species, such as $M$. sinensis (Christian et al. 2005). This is economically attractive, as it will likely lower the cost of planting with a better establishment and speed up the development of Miscanthus as a dedicated biomass crop.

The genetic improvement by conventional breeding has been used to improve traits of many species, but its success has been limited by barriers to sexual reproduction and the relatively long time periods required for breeding programs. More recently, genetic engineering methods with the help of transformation technologies have been used to improve many species more efficiently, whereby useful traits have been introduced from a broader range of sources within an economically viable time frame (Jakob et al.
2009; Takahashi and Takamizo 2012). Transformation is an important tool for improving the performance of crop species and effective transformation techniques should allow for the incorporation of foreign genes that improve crop traits efficiently. In the case of Miscanthus species, there have been several reports related to tissue culture conditions for callus induction and plant regeneration (Głowacka and Jeżowski 2009; Park et al. 2009; Głowacka et al. 2010; Kim et al. 2010; Płażek and Dubert 2010; Zhang et al. 2012), but there has been only one recent report on success of genetic transformation of M. sinensis using particle bombardment (Wang et al. 2011). However, particle bombardment-mediated transformation method has demonstrated certain disadvantages, including a low frequency of success and the insertion of multiple gene copies, which is thought to correlate with gene silencing, while the Agrobacterium-mediated transformation method can overcome some of these disadvantages, such as transgene copy number and cost (Dai et al. 2001). Therefore, it is highly necessary to develop an Agrobacterium-mediated transformation method for Miscanthus species.

The objective of this study was to develop an Agrobacterium-mediated genetic transformation system for $M$. sinensis, and to produce herbicide-resistant Miscanthus plants using the method. Here, a method for the stable Agrobacterium-mediated transformation of $M$. sinensis was established using a hygromycin resistance gene $(H Y G)$ as a selectable marker and an enhanced green fluorescence protein gene (egfp) as a reporter, which delivers transgenes that are stably integrated and expressed. Then, we applied the transformation system with a vector containing an herbicide resistance gene $(B A R)$ as a selectable marker, and successfully obtained transgenic plants with herbicide resistance. This approach will be useful for the development of genetically engineered Miscanthus species with enhanced agricultural performance.

\section{Materials and methods}

Plant materials

Commercial seeds of $M$. sinensis were purchased from Geumo Landscape Development Co. Ltd. and used for the optimization of conditions for tissue culture and plant regeneration. Seeds of seven $M$. sinensis germplasms maintained at Seoul National University (SNU) were used for the development of the genetic transformation system. These germplasms were collected from several places in Korea (Table 1 and Supplementary Table 1). Prior to use, the seeds were stored at $4{ }^{\circ} \mathrm{C}$. 
Table 1 Origin of seven germplasms of $M$. sinensis used in the present study

\begin{tabular}{|c|c|c|c|c|}
\hline $\begin{array}{l}\text { Germplasm } \\
\text { code }\end{array}$ & Latitude & Longitude & $\begin{array}{l}\text { Altitude } \\
(\mathrm{m})\end{array}$ & Collecting site \\
\hline SNU-M-022 & $\mathrm{N} 38^{\circ} 04^{\prime}$ & $\mathrm{E} 127^{\circ} 20^{\prime}$ & 655 & $\begin{array}{l}\text { Mt. Myung-Seong, } \\
\text { Korea }\end{array}$ \\
\hline SNU-M-025 & $\mathrm{N} 38^{\circ} 04^{\prime}$ & $\mathrm{E} 127^{\circ} 20^{\prime}$ & 579 & $\begin{array}{l}\text { Mt. Myung-Seong, } \\
\text { Korea }\end{array}$ \\
\hline SNU-M-032 & $\mathrm{N} 33^{\circ} 17^{\prime}$ & $\mathrm{E} 126^{\circ} 32^{\prime}$ & 404 & Jeju, Korea \\
\hline SNU-M-034 & $\mathrm{N} 33^{\circ} 19^{\prime}$ & $\mathrm{E} 126^{\circ} 36^{\prime}$ & 359 & Jeju, Korea \\
\hline SNU-M-037 & $\mathrm{N} 33^{\circ} 26^{\prime}$ & $\mathrm{E} 126^{\circ} 33^{\prime}$ & 430 & Jeju, Korea \\
\hline SNU-M-045 & $\mathrm{N} 37^{\circ} 31^{\prime}$ & $\mathrm{E} 126^{\circ} 32^{\prime}$ & 5 & Incheon, Korea \\
\hline SNU-M-107 & $\mathrm{N} 35^{\circ} 31^{\prime}$ & $\mathrm{E} 128^{\circ} 53^{\prime}$ & 86 & Milyang, Korea \\
\hline
\end{tabular}

Induction of embryogenic calli and plant regeneration

Mature seeds were used for the induction of embryogenic calli. For sterilization of the seeds, de-husked seeds were first soaked in $0.1 \%$ Benlate (Syngenta Korea, Seoul) for $5 \mathrm{~h}$, and the Benlate-treated seeds were sterilized in $70 \%$ (v/v) ethanol for $5 \mathrm{~min}$, followed by $2 \%(\mathrm{w} / \mathrm{v})$ sodium hypochlorite for $20 \mathrm{~min}$ with shaking. The seeds were then rinsed more than five times in sterile distilled water and placed on callus induction medium (CIM) containing MS salts and vitamins, $30 \mathrm{~g} \mathrm{~L}^{-1}$ sucrose, $750 \mathrm{mg} \mathrm{L}^{-1}$ $\mathrm{MgCl}_{2} \cdot 6 \mathrm{H}_{2} \mathrm{O}, 2 \mathrm{~g} \mathrm{~L}^{-1}$ Gelrite, and other factors to be examined. To optimize the conditions for embryogenic callus induction, CIM with various combinations of phytohormones [1, 2 or $3 \mathrm{mg} \mathrm{L}^{-1}$ 2,4-dichlorophenoxyacetic acid (2,4-D) and $0,0.01,0.05$ or $0.1 \mathrm{mg} \mathrm{L}^{-1}$ 6-benzyladenine (BA)] and $\mathrm{pH}(5.5,5.7$, or 5.9) were tested for callus induction at different temperatures $(25,28$, or $30{ }^{\circ} \mathrm{C}$ ), and the embryogenic calli were visually investigated. The $\mathrm{pH}$ of the medium was adjusted prior to autoclaving at $121{ }^{\circ} \mathrm{C}$ for $15 \mathrm{~min}$. Approximately 200 seeds were placed on eight petri dishes in each condition and tested for the callus induction with three replicates. Cultures were maintained in the dark, and subcultured at 2-week intervals for 8 weeks. The percentage of callus induction was examined after 4 weeks in culture using the number of induced calli from seeds, and the percentage of embryogenic calli was calculated after 8 weeks in culture using the number of embryogenic calli from all induced calli.

In addition, the effect of L-proline on the production of embryogenic calli and callus growth was investigated using various concentrations of L-proline in CIM containing $3 \mathrm{mg} \mathrm{L}^{-1} 2,4-\mathrm{D}$. For this test, the $\mathrm{pH}$ of the medium was adjusted to 5.7 , and cultures were maintained at $28{ }^{\circ} \mathrm{C}$ in the dark with subculture at 2 -week intervals. For the investigation of the production of embryogenic calli, the percentages of callus induction and embryogenic calli were examined after 4 and 6 weeks in culture, respectively. For the investigation of callus growth, twenty pieces (3-4 mm diameter) of 8-week-old embryogenic callus per plate (three plates per treatment) were weighed before and 2 weeks after culture in the dark at $28{ }^{\circ} \mathrm{C}$. The growth index was calculated as the final fresh weight minus the initial fresh weight, and divided by the initial fresh weight.

To test the plant regeneration potentials of the induced calli, 8-week-old calli (3-4 mm diameter) were transferred onto plant regeneration medium [MS salts and vitamins, $2 \mathrm{mg} \mathrm{L}^{-1}$ kinetin, $30 \mathrm{~g} \mathrm{~L}^{-1}$ sucrose, $750 \mathrm{mg} \mathrm{L}^{-1}$ $\mathrm{MgCl}_{2} \cdot 6 \mathrm{H}_{2} \mathrm{O}$, and $2 \mathrm{~g} \mathrm{~L}^{-1}$ Gelrite (pH 5.7)]. $2 \mathrm{mg} \mathrm{L}^{-1} \mathrm{ki}-$ netin was included in the regeneration medium, based on a previous report for the regeneration of $M$. sinensis (Park et al. 2009). The percentage of regeneration was calculated using the number of embryogenic calli with shoot formation on regeneration medium after 4 weeks. In addition, plantlets with developed roots were counted after 8 weeks in culture to examine the number of plantlets per callus.

Agrobacterium strain and plasmids used for genetic transformation

A gene cassette consisting of an enhanced green fluorescence protein gene (egfp) under the control of maize ubiquitin promoter $\left(\mathrm{P}_{\mathrm{ubi}}\right)$ and Agrobacterium tumefaciens nos gene terminator was subcloned into the binary vector pCAMBIA1300 using HindIII and SmaI. For the gene cassette, ubiquitin promoter was subcloned from pCAMBIA3301 harboring $\mathrm{P}_{\mathrm{ubi}}:: L c$ in our previous report (Han et al. 2009) into pCAMBIA1300 using HindIII and BamHI. Then, the egfp gene and nos gene terminator was subcloned from pCSVMV-eGFP-N-999 (Kim et al. 2008) into downstream of the ubiquitin promoter using BamHI and SmaI. The vector carries a hygromycin phosphotransferase II gene (HPTII or $H Y G$ ) under the control of the cauliflower mosaic virus $35 \mathrm{~S}$ promoter $\left(\mathrm{P}_{35 \mathrm{~S}}\right)$ for hygromycin resistance as a selectable marker, and the egfp gene in the vector was used as a reporter (Supplementary Fig. 1a). The binary vector DNA was then used to introduce into A. tumefaciens strain EHA105 by the freeze-thaw method (Chen et al. 1994). Therefore, A. tumefaciens EHA105 containing the binary vector pCAMBIA1300 with egfp gene was used for the development of genetic transformation system for $M$. sinensis.

For the production of herbicide-resistant $M$. sinensis, pCAMBIA3301 carrying the BAR gene for herbicide resistance was used (Supplementary Fig. 1b). The BAR gene encodes a phosphinotricin acetyltransferase that confers resistance to the herbicides phosphinotricin (PPT) and bialaphos (phosphinotricyl-alanyl-alanine or glufosinate) by inhibiting glutamine synthase, and thus interfering with amino acid biosynthesis. This $B A R$ gene was also used as a selectable marker during the transformation. 
Agrobacterium-mediated transformation

To develop the Agrobacterium-mediated genetic transformation system of $M$. sinensis, embryogenic calli of the germplasm SNU-M-045 were induced and cultured at $28{ }^{\circ} \mathrm{C}$ on optimized CIM [MS salts and vitamins, $3 \mathrm{mg} \mathrm{L}^{-1}$ 2,4-D, $30 \mathrm{~g} \mathrm{~L}^{-1}$ sucrose, $750 \mathrm{mg} \mathrm{L}^{-1} \mathrm{MgCl}_{2}$. $6 \mathrm{H}_{2} \mathrm{O}, 25 \mathrm{mM}$ L-proline, and $2 \mathrm{~g} \mathrm{~L}^{-1}$ Gelrite (pH 5.7)] for 8-10 weeks. A. tumefaciens EHA105 harboring pCAMBIA1300 with egfp gene were grown at $28{ }^{\circ} \mathrm{C}$ in liquid Luria-Bertani (LB) medium (Difco, USA). At $\mathrm{OD}_{600}=$ 0.8 , cells were harvested by centrifugation at $3,000 \mathrm{rpm}$ for $15 \mathrm{~min}$, and then re-suspended in an equal volume of inoculation media for $4 \mathrm{~h}$. The inoculation media with different $\mathrm{pH}(5.2,5.5$ or 5.7) and acetosyringone concentrations (200 or $400 \mu \mathrm{M}$ ) were used to find the optimum conditions for the inoculation. The embryogenic calli were then immersed in Agrobacterium suspensions and incubated for $15 \mathrm{~min}$ with gentle shaking, followed by the removal of excess bacteria and air-drying on filter paper. The inoculated calli were then transferred onto co-cultivation medium [MS salts and vitamins, $3 \mathrm{mg} \mathrm{L}^{-1}$ 2,4-D, $20 \mathrm{~g} \mathrm{~L}^{-1}$ sucrose, $10 \mathrm{~g} \mathrm{~L}^{-1}$ glucose, $400 \mu \mathrm{M}$ acetosyringone, and $3 \mathrm{~g} \mathrm{~L}^{-1}$ Gelrite ( $\mathrm{pH}$ 5.7)] and incubated in the dark at $25{ }^{\circ} \mathrm{C}$ for 3 or 5 days. After co-cultivation, the calli were then transferred onto selection medium (CIM with $250 \mathrm{mg} \mathrm{L}^{-1}$ cefotaxime and $50 \mathrm{mg} \mathrm{L}^{-1}$ hygromycin), and cultured for 6 weeks in the dark. For shoot induction, surviving calli on the selection medium were transferred onto regeneration medium [MS salts and vitamins, $2 \mathrm{mg} \mathrm{L}^{-1}$ kinetin, $30 \mathrm{~g} \mathrm{~L}^{-1}$ sucrose, $750 \mathrm{mg} \mathrm{L}^{-1} \mathrm{MgCl}_{2}$. $6 \mathrm{H}_{2} \mathrm{O}, \quad 25 \mathrm{mM}$ L-proline, $250 \mathrm{mg} \mathrm{L}^{-1}$ cefotaxime, $30 \mathrm{mg} \mathrm{L}^{-1}$ hygromycin, and $2 \mathrm{~g} \mathrm{~L}^{-1}$ Gelrite (pH 5.7)] for $8-16$ weeks under cool-white fluorescent lamps at $25^{\circ} \mathrm{C}$ in a culture room. Regenerated shoots from calli were finally transferred on root induction medium [1/2MS salts and vitamins, $20 \mathrm{~g} \mathrm{~L}^{-1}$ sucrose, $750 \mathrm{mg} \mathrm{L} \mathrm{MgCl}_{2} \cdot 6 \mathrm{H}_{2} \mathrm{O}$, $125 \mathrm{mg} \mathrm{L}^{-1}$ cefotaxime, and $2 \mathrm{~g} \mathrm{~L}^{-1}$ Gelrite ( $\mathrm{pH}$ 5.7)], and plantlets with well-developed roots were then placed in soil and grown under greenhouse conditions.

During the transformation process, GFP expression was examined to determine if the embryogenic calli were transformed. The plates with transgenic calli were placed under a UV lamp in a dark room, and the GFP signals were detected by an Illumatool LT-9000 Bright Light system (Lightools Research, CA, USA).

Molecular analyses of transgenic $M$. sinensis plants

Genomic PCR, DNA gel blot, and Northern blot analyses of transgenic plants were performed as previously described (Han et al. 2009, 2012). For genomic PCR analysis, total genomic DNA was isolated from the leaves of greenhouse-grown plants, and the coding region for the egfp, $H Y G$ or $B A R$ transgene was amplified by PCR from either genomic DNA or a positive-control vector, using the following sets of oligonucleotide primers: $5^{\prime}$-CCTACGG CGTGCAGTGCTTCAGC-3' (forward) and 5'-CGGCGA GCTGCACGCTGC GTCCTC- $3^{\prime}$ (reverse) for $e g f p, 5^{\prime}$-CT CCTCCATACAAGCCAACCAC- $3^{\prime}$ (forward) and $5^{\prime}$-GC GAAGAATCTCGTGCTTTCAG-3' (reverse) for $H Y G$, and 5'-CTACCATGAGCCCAGAACGACG-3' (forward) and 5'-CTGCCAGAAACCCACGTCATGCCAGTTC- $3^{\prime}$ (reverse) for BAR. The actin gene (ACT) of M. sinensis was also amplified using the same template and the primers $5^{\prime}$-AACTGGGATGATATGGAGAA- $3^{\prime}$ (forward) and $5^{\prime}$-CCTCCAATCCAGACACTGTA- ${ }^{\prime}$ (reverse), and then run as a loading control of genomic DNA. The PCR products of egfp, $H Y G, B A R$, and $A C T$ were expected to be $356,641,421$, and $1,046 \mathrm{bp}$, respectively.

For the DNA gel blot analysis, $15 \mu \mathrm{g}$ of genomic DNA was digested with either HindIII or BamHI, and hybridizations were carried out with the $H Y G$ gene probe that was labeled with $\left[\alpha^{32} \mathrm{P}\right] \mathrm{dCTP}$ using the Radiprime ${ }^{\mathrm{TM}}$ II Random Prime Labeling System (Amersham Biosciences, UK). For Northern blot analysis, total RNA was extracted from leaves using Trizol reagent (Invitrogen, CA, USA), and hybridizations were carried out with $\left[\alpha^{32} \mathrm{P}\right] \mathrm{dCTP}-$ labeled $H Y G$ or $B A R$ probe.

\section{Generation of herbicide-resistant $M$. sinensis plants}

For the development of herbicide-resistant $M$. sinensis plants, mature seed-derived embryogenic calli and $A$. tumefaciens EHA105 harboring pCAMBIA3301 were used for the genetic transformation. Basically, transformation conditions optimized in the transformation with the hygromycin resistance selection marker were applied (see Supplemantary Table S3 for the optimized transformation conditions for $M$. sinensis). After transformation, transgenic calli were selected on the selection medium containing $5 \mathrm{mg} \mathrm{L}^{-1} \mathrm{PPT}$ in the dark for 3 weeks and also in the light for additional 3 weeks. Then, transgenic shoots were induced on the regeneration medium with $3 \mathrm{mg} \mathrm{L}^{-1}$ PPT. Plantlets with well-developed roots were established in soil and grown for 2 weeks, prior to herbicide treatment. Herbicide resistance assay was performed by spraying $0.4 \%(\mathrm{v} / \mathrm{v})$ BASTA $^{\circledR}$ (which contains $18 \%$ glufosinate ammonium), and the herbicide resistance of plants was determined after 7 or 14 days.

Statistical analysis

The data of callus induction experiments were analyzed using ANOVA with IBM SPSS statistics 20 software. Significant differences from the control values were 
determined at $P<0.05$. All of the data were represented as the mean $\pm \mathrm{SD}$ or $\mathrm{SE}$ of at least three independent experiments.

\section{Results}

Induction of embryogenic calli for plant regeneration and genetic transformation

Establishing an efficient regeneration system is fundamental for the genetic manipulation of any species, and callus quality is important for the successful regeneration and genetic transformation of plants (Kim et al. 2007; Li and $\mathrm{Qu}$ 2011). Embryogenic callus tissue derived from mature seeds has previously been used for Agrobacteriummediated transformation of several monocotyledons, and is considered to be the best target tissue for genetic transformation as it is actively dividing (Cheng et al. 2004). In this study, we first investigated the callus induction from mature seeds of $M$. sinensis, which were purchased from Geumo Landscape Development Co., Ltd. For the optimization of embryogenic callus induction conditions, various combinations of phytohormones $\left[1,2\right.$ or $3 \mathrm{mg} \mathrm{L}^{-1}$ 2,4-D and $0,0.01,0.05$ or $\left.0.1 \mathrm{mg} \mathrm{L}^{-1} \mathrm{BA}\right], \mathrm{pH}(5.5,5.7$ or 5.9), and temperature $\left(25,28\right.$ or $\left.30^{\circ} \mathrm{C}\right)$ were applied to the callus induction step, and the percentages of callus induction were calculated using the number of induced calli from seeds. In addition, since the formation of embryogenic calli within the induced calli is important for further plant regeneration and genetic transformation steps, we also calculated the percentages of embryogenic calli using the number of embryogenic calli (i.e., those with regeneration potential) from all induced calli. In the case of callus induction, the results showed that no significant difference was detected at different $\mathrm{pH}$ and temperatures except a slight decrease in pH 5.9 (Fig. 1a, b and Supplementary Fig. 2). On the other hand, when the percentages of embryogenic calli were compared, the use of $\mathrm{pH} 5.7$ was better than $\mathrm{pH} 5.5$ or 5.9 , and $28{ }^{\circ} \mathrm{C}$ was better than 25 or $30{ }^{\circ} \mathrm{C}$. It is notable that increases in callus browning and percentages of non-embryogenic transparent calli were observed in higher $\mathrm{pH}$ and temperature, which might decrease the percentages of embryogenic calli. The results also showed that the addition of BA reduced the percentages of callus induction and embryogenic calli (Supplementary Fig. 2 and Fig. 1c). The percentages of callus induction ranged from 52.5 to $71.1 \%$ in the absence of $\mathrm{BA}$, but the addition of BA reduced the percentages in all tested conditions. More importantly, the percentages of embryogenic calli were also reduced in the presence of BA. Among the tested conditions, the conditions of $3 \mathrm{mg} \mathrm{L}^{-1}$ 2,4-D and $\mathrm{pH} 5.7$ at $28{ }^{\circ} \mathrm{C}$ were the most effective in
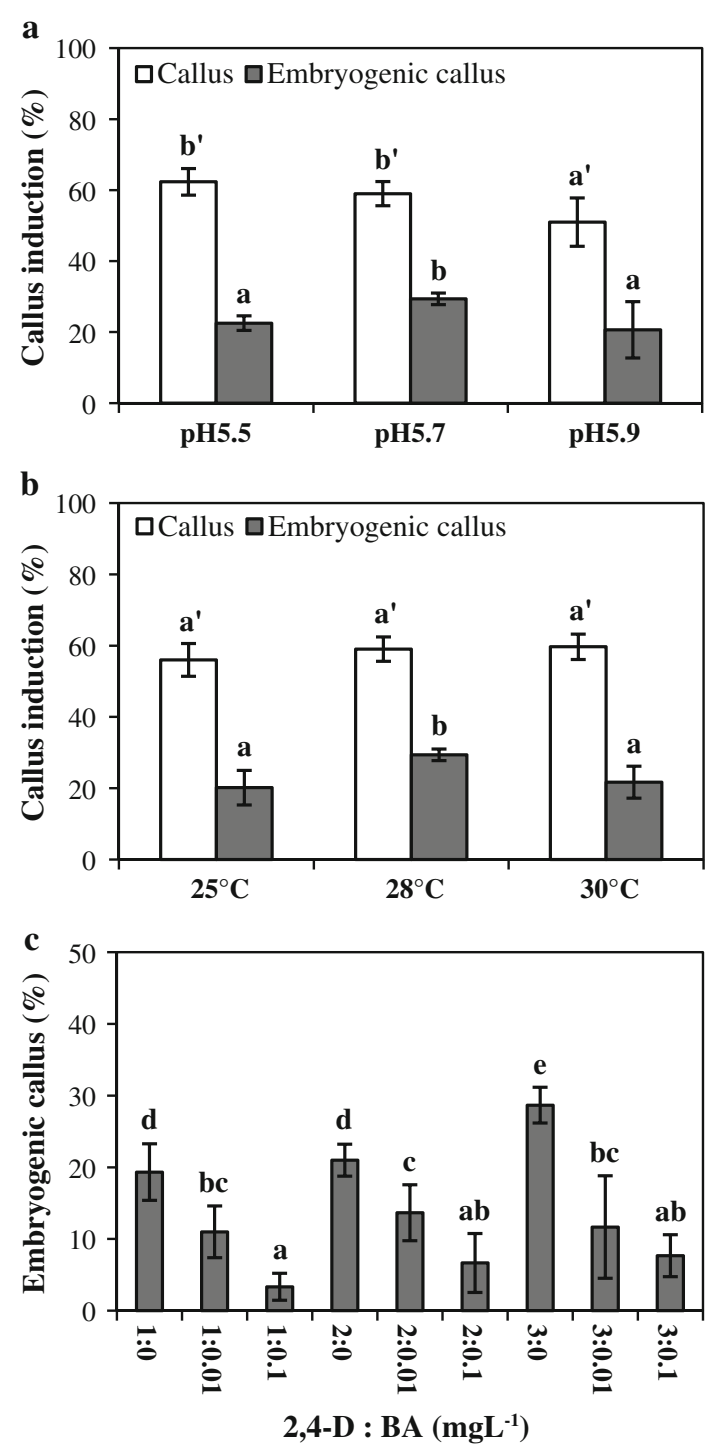

Fig. 1 Effects of pH, temperature, and combinations of 2,4-dichlorophenoxyacetic acid (2,4-D) and 6-benzyl-adenine (BA) on callus induction or embryogenic callus induction. a Effects of $\mathrm{pH}$. Callus was induced from mature seeds on CIM containing $3 \mathrm{mg} \mathrm{L}^{-1} 2,4-$ D and different $\mathrm{pH}$ at $28^{\circ} \mathrm{C}$. b Effects of temperature. Callus was induced on CIM containing $3 \mathrm{mg} \mathrm{L}^{-1}$ 2,4-D with $\mathrm{pH} 5.7$ at different temperatures. c Effects of 2,4-D: BA combinations. Callus was induced on CIM containing various hormone combinations with $\mathrm{pH}$ 5.7 at $28{ }^{\circ} \mathrm{C}$. Error bars indicate standard deviations of three replicates. Means with different letters are significantly different at $P<0.05$, using Duncan

embryogenic callus induction (approximately $30 \%$ ) compared with other induction conditions (Fig. 1c). Therefore, optimized CIM containing MS salts and vitamins, $3 \mathrm{mg} \mathrm{L}^{-1}$ 2,4-D, $30 \mathrm{~g} \mathrm{~L}^{-1}$ sucrose, $750 \mathrm{mg} \mathrm{L}^{-1} \mathrm{MgCl}_{2}$. $6 \mathrm{H}_{2} \mathrm{O}, 2 \mathrm{~g} \mathrm{~L}^{-1}$ Gelrite ( $\mathrm{pH}$ 5.7), and induction temperature of $28{ }^{\circ} \mathrm{C}$ were used for further experiments.

There have been previous reports that the addition of $\mathrm{L}^{-}$ proline increases the induction and growth of embryogenic calli (Holme et al. 1997; Kim et al. 2010; Li and Qu 2011). 


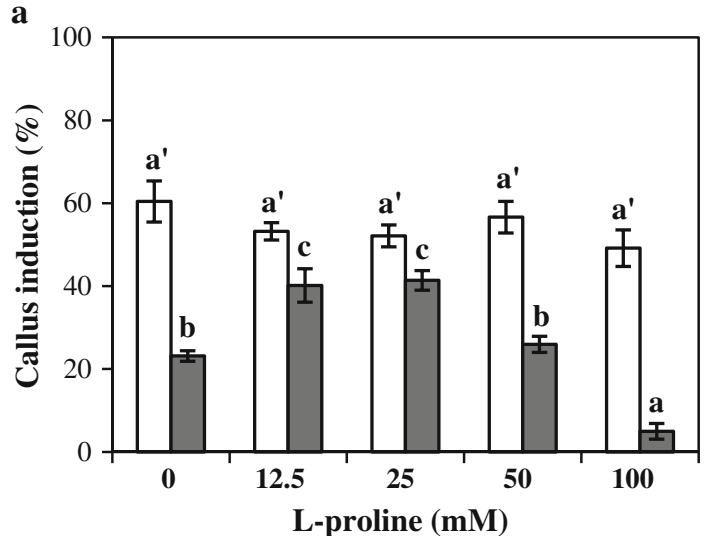

b

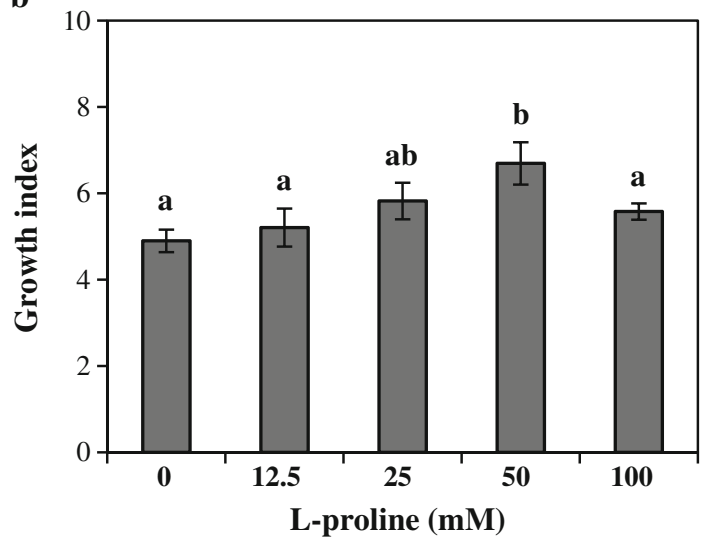

Fig. 2 Effects of L-proline on embryogenic callus induction and callus growth. a Effect of L-proline on the induction of embryogenic callus. The percentages of callus induction (open bars) and embryogenic callus (filled bars) were calculated after 6 weeks in culture. b Effect of L-proline on callus growth. The growth index is calculated from increased fresh weight of callus divided by initial fresh weight. Error bars indicate standard deviations of three replicates. Means with different letters are significantly different at $P<0.05$, using Duncan

Thus, the effects of L-proline on the callus induction and the growth of embryogenic calli were investigated using various concentrations of L-proline. Results showed that the addition of L-proline had little effect on callus induction, but significant effect on the induction of embryogenic calli (Fig. 2a). When the embryogenic callus induction was evaluated 6 weeks after callus induction, the addition of 12.5 or $25 \mathrm{mM}$ L-proline significantly increased the percentages of embryogenic calli compared to when none was added, or when more than $25 \mathrm{mM}$ L-proline was added. Furthermore, when the growth of callus was investigated in various concentrations of L-proline, the supplement of 25 or $50 \mathrm{mM} \mathrm{L}$ proline showed higher callus growth than that of none or $12.5 \mathrm{mM}$ L-proline (Fig. 2b). Based on the results of the induction and growth of embryogenic calli, we added $25 \mathrm{mM} \mathrm{L}$-proline to the callus induction medium afterwards.

During the callus induction, different types of embryogenic calli were observed. It is known that an embryogenic callus is compact and friable, whereas soft and watery calli are not embryogenic (Wang et al. 2011). Thus, we checked the types of induced calli, and found three embryogenic callus types: yellowish compact, whitish friable, and whitish compact types (Fig. 3). They showed different regeneration potentials, with the yellowish compact type having the highest potential $(73.53 \%, 25$ calli with shoot formation of 34 calli), followed by the whitish friable type with moderate potential $(43.48 \%, 20$ calli with shoots from 46 calli), and the whitish compact type with the lowest potential $(33.33 \%, 12$ calli with shoots from 36 calli). In addition, the yellowish compact type calli showed superior formation of multiple shoots during the regeneration. When the number of plantlets per callus was observed, averages of 13.0, 5.7 and 4.3 plantlets per callus were obtained from the three embryogenic callus types, respectively. Based on the results that the yellowish compact type calli showed the highest regeneration potentials with multiple shoot formation, they were used to investigate the conditions for genetic transformation.

Comparisons of embryogenic callus induction and regeneration potentials among seven germplasms of $M$. sinensis

Miscanthus sinensis is an outbreeding and self-incompatible species. The commercial seeds purchased from Geumo Landscape Development Co., Ltd. (Hereafter, Geumo seeds) were known to be collected from different places in Korea, so they were kinds of mixed seeds obtained from different $M$. sinensis varieties. Although we tried to develop a genetic transformation system of $M$. sinensis using the Geumo seeds, we failed to obtain transgenic plants with these seeds, probably due to genetic heterogeneity of the Geumo seeds. Previous reports also suggested the importance of genotypes in callus induction, plant regeneration and genetic transformation (Somleva et al. 2008; Głowacka et al. 2010; Wang et al. 2011). Thus, we obtained seven germplasms of $M$. sinensis which were maintained at Seoul National University (SNU), and investigated the induction of embryogenic calli and their regeneration to find a good candidate for the genetic transformation. The germplasms were collected in Korea within the latitudinal range of $\mathrm{N} 33^{\circ}$ (Jeju) to $\mathrm{N} 38^{\circ}$ (Mt. Myung-Seong) and the altitudinal range of 5-655 m (Table 1). Compared with Geumo seeds, the results of embryogenic callus induction showed that two germplasms (SNU-M-025 and SNU-M-045) had significantly higher induction percentages of embryogenic calli (Table 2). Their embryogenic callus percentages were more than $50 \%$, which was much higher than that of Geumo seeds $(34.33 \%)$. When the regeneration potentials were compared, SNU-M-022 and SNU-M-045 germplasms showed 


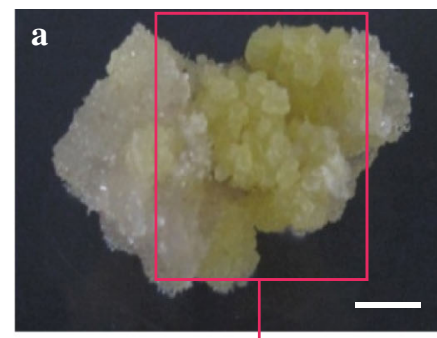

7
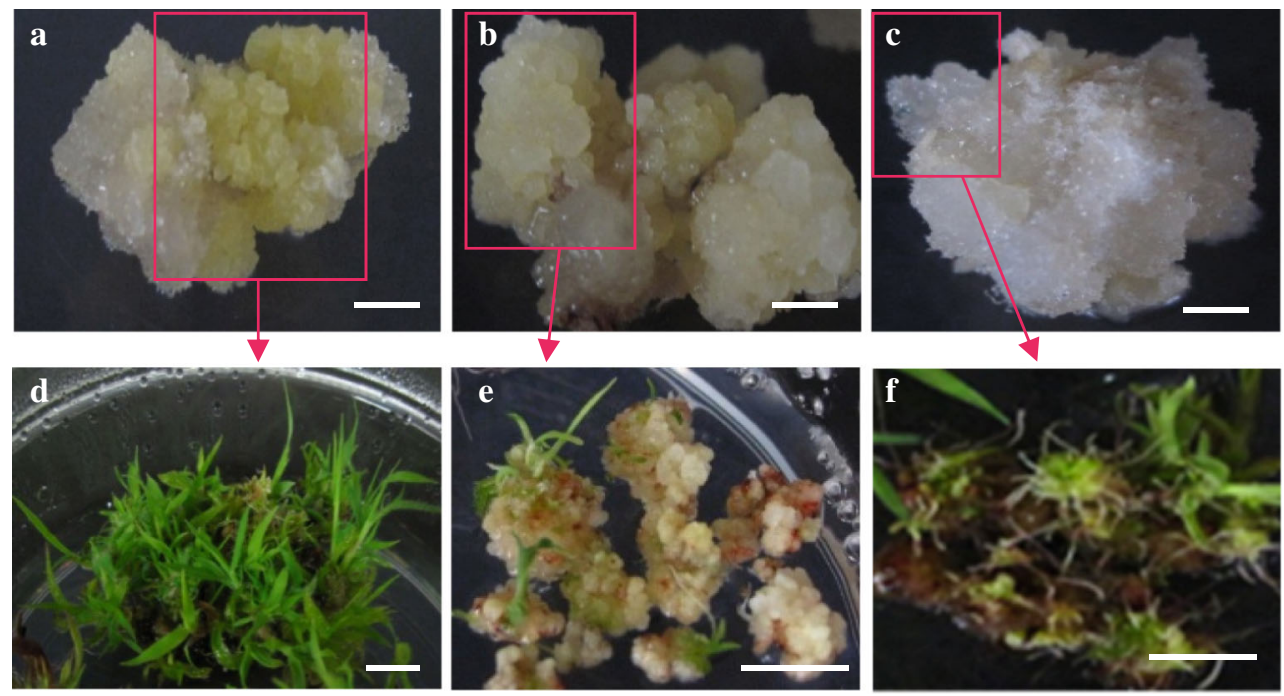

7
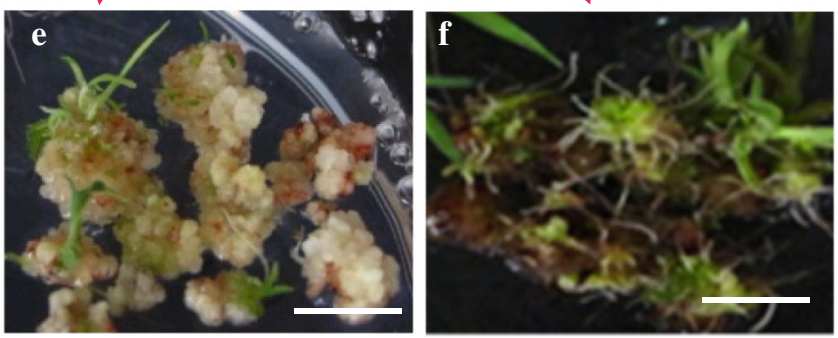

Fig. 3 Comparison of plant regeneration from different callus types. Three types of embryogenic calli were identified by color and texture: yellowish compact type (a), whitish friable type (b), and whitish compact type (c). d-f Shoot formation from regeneration of yellowish compact, whitish friable, and whitish compact types of calli, respectively. Bar $1 \mathrm{~mm}(\mathbf{a}-\mathbf{c})$ or $1 \mathrm{~cm}(\mathbf{d}-\mathbf{f})$. (Color figure online)
Table 2 Comparisons of embryogenic callus induction and plant regeneration among seven germplasms of $M$. sinensis used in the present study

\begin{tabular}{lcc}
\hline Germplasm code & $\begin{array}{l}\text { Embryogenic callus } \\
\text { induction }(\%)^{\dagger}\end{array}$ & Regeneration $(\%)^{\dagger}$ \\
\hline Geumo & $34.33 \pm 1.25^{\mathrm{b}}$ & $53.09 \pm 11.20^{\mathrm{b}}$ \\
SNU-M-022 & $31.00 \pm 4.08^{\mathrm{b}}$ & $82.64 \pm 0.98^{\mathrm{a}}$ \\
SNU-M-025 & $55.33 \pm 3.68^{\mathrm{a}}$ & $23.96 \pm 5.31^{\mathrm{d}}$ \\
SNU-M-032 & $13.33 \pm 3.09^{\mathrm{c}}$ & $28.82 \pm 5.40^{\mathrm{cd}}$ \\
SNU-M-034 & $15.91 \pm 4.92^{\mathrm{c}}$ & $38.89 \pm 6.38^{\mathrm{c}}$ \\
SNU-M-037 & $8.30 \pm 0.94^{\mathrm{c}}$ & $5.21 \pm 1.70^{\mathrm{e}}$ \\
SNU-M-045 & $52.67 \pm 5.31^{\mathrm{a}}$ & $86.11 \pm 8.56^{\mathrm{a}}$ \\
SNU-M-107 & $29.00 \pm 1.63^{\mathrm{b}}$ & $22.20 \pm 2.14^{\mathrm{d}}$ \\
\hline
\end{tabular}

${ }^{\dagger}$ All of the data represent the mean \pm SD of three independent experiments. The data with different letters in each column are significantly different at $P<0.05$, using Duncan

82.64 and $86.11 \%$, respectively, which were much better than Geumo seeds (53.09\%) (Table 2 and Supplementary Fig. 3). Collectively, the results of embryogenic callus induction and plant regeneration showed that the SNU-M045 germplasm was the superior candidate for the development of a genetic transformation method for M. sinensis, because this germplasm showed a much higher combination ratio of embryogenic callus induction and regeneration potential than other germplasms (Table 2). In addition, this germplasm showed the ability to form multiple shoots from embryogenic calli during regeneration (Supplementary Fig. 3). Therefore, the genetic transformation system of $M$. sinensis was developed with the SNU-M-045 germplasm.
Establishment of Agrobacterium-mediated transformation system for $M$. sinensis

For the genetic transformation of M. sinensis, embryogenic calli were induced from the optimized CIM [MS salts and vitamins, $3 \mathrm{mg} \mathrm{L}^{-1}$ 2,4-D, $30 \mathrm{~g} \mathrm{~L}^{-1}$ sucrose, $750 \mathrm{mg} \mathrm{L}^{-1}$ $\mathrm{MgCl}_{2} \cdot 6 \mathrm{H}_{2} \mathrm{O}, 25 \mathrm{mM}$ L-proline, and $2 \mathrm{~g} \mathrm{~L}^{-1}$ Gelrite $(\mathrm{pH}$ 5.7)] at $28^{\circ} \mathrm{C}$, and yellowish compact type calli were selected visually, followed by Agrobacterium inoculation. Based on our previous experiences on the establishment of Agrobacterium-mediated transformation system for a grass, creeping bentgrass (Kim et al. 2007; Han et al. 2009, 2012; Cho et al. 2011), the Agrobacterium-mediated transformation conditions of creeping bentgrass were basically applied to $M$. sinensis transformation, with some modifications. In this study, GFP signals were investigated on transformed calli during the selection step to investigate factors that could influence the transformation (Supplementary Fig. 4). We checked the effects of medium $\mathrm{pH}$ and acetosyringone concentration during Agrobacterium inoculation, and also the periods of co-cultivation on transformation. The results showed that conditions with a medium $\mathrm{pH}$ of 5.2, $400 \mu \mathrm{M}$ acetosyringone, and 5 days of co-cultivation generated more transformed calli with GFP signals (Supplementary Table 2). Thus, we applied these conditions for further establishing the genetic transformation system of M. sinensis.

Using the optimum conditions for embryogenic callus induction and Agrobacterium inoculation, we then performed Agrobacterium-mediated genetic transformation with the SNU-M-045 germplasm seeds (Fig. 4 and Supplementary Table 3). Since we used pCAMBIA1300 

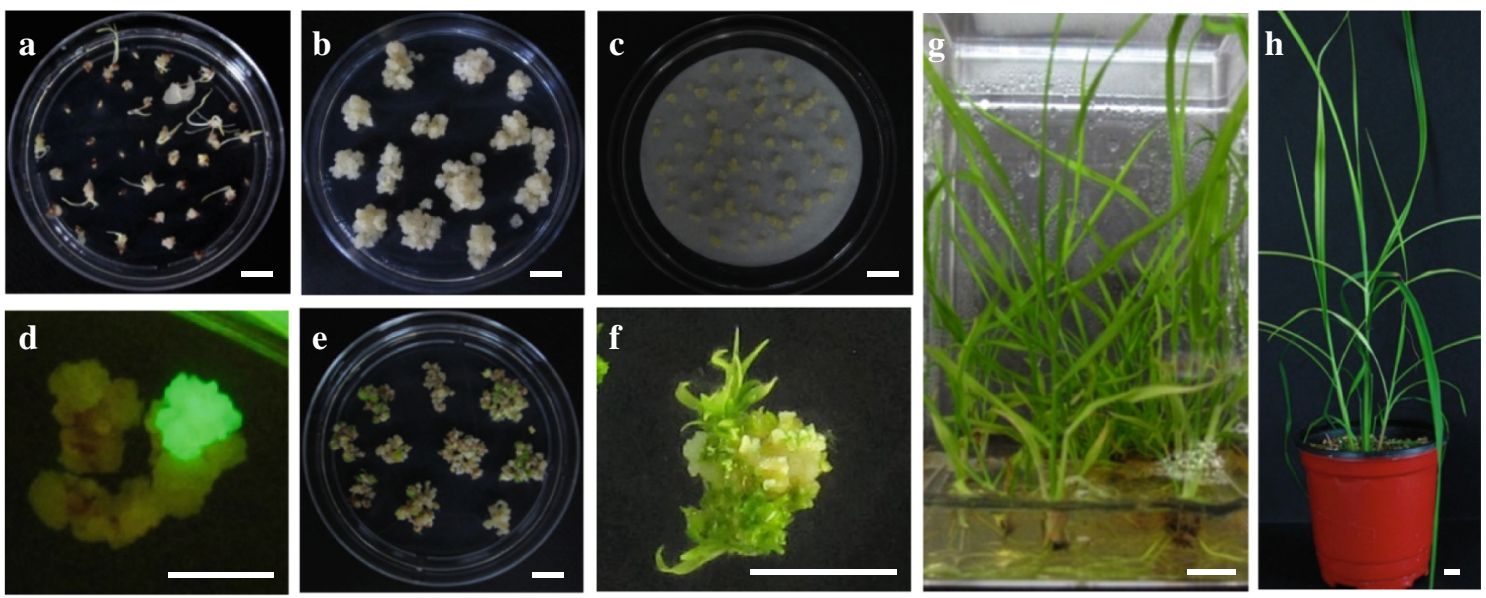

Fig. 4 Production of transgenic $M$. sinensis plants by Agrobacteriummediated transformation. The SNU-M-045 germplasm of $M$. sinensis was used for this transformation. a Calli induced from mature seeds on callus induction medium. b Selection and propagation of embryogenic calli. c Co-cultivation of selected embryogenic calli

containing the hygromycin phosphotransferase II gene $(H Y G)$ as a selectable marker, we initially examined the minimum concentrations of hygromycin that prevent plant regeneration of non-transformed calli, and found that the addition of $30-50 \mathrm{mg} \mathrm{L}^{-1}$ hygromycin inhibited the regeneration. Thus, transgenic calli were selected with $50 \mathrm{mg} \mathrm{L}^{-1}$ hygromycin. During the incubation of Agrobacterium-inoculated calli on selection media, only hygromycin-resistant calli grew and generated green shoots (Fig. 4e). In contrast, hygromycin-sensitive calli died and usually became dark brown in color. On shoot induction media containing $30 \mathrm{mg} \mathrm{L}^{-1}$ hygromycin, multiple shoots usually emerged from hygromycin-resistant calli (Fig. 4ef), and after being transferred onto root induction media, the growth of plantlets with roots were observed (Fig. 4g). Plantlets with well-developed roots were then transferred to soil and grown under greenhouse conditions before further analysis (Fig. 4h). The putative transgenic plants appeared normal under greenhouse conditions, and were morphologically indistinguishable from non-transformed control plants.

To confirm whether the obtained plants were transgenic, genomic PCR analysis was initially performed on DNA extracted from the leaves of putative transgenic plants using egfp and $H Y G$ primers to test for the presence of the transgenes (Fig. 5a). All the plants obtained from the transformation procedures contained both egfp and $H Y G$ transgenes, which confirmed that they were transgenic plants. Next, Northern blot analysis was performed to confirm the expression of $H Y G$ gene in the transgenic plants (Fig. 5b). The results showed that all the transgenic plants exhibited similar levels of $H Y G$ expression, whereas no hybridization was detected in the control samples (NT). with Agrobacterium suspensions. d GFP expression on transformed calli. e Shoot induction from transformed calli. f Amplified picture of induced shoots. g Root induction from hygromycin-resistant shoots. h Putative transgenic plant grown in greenhouse. Bar $1 \mathrm{~cm}$

Finally, DNA gel blot analysis was performed to assess the stable integration of the $H Y G$ gene in transgenic plants (Fig. 5c). Results showed that all the transgenic plants contained one genomic copy of $H Y G$, whereas no hybridization signal was detected from the control plant (NT). Since transgenic events \#2 and \#3 showed the same band patterns, and transgenic events \#5 and \#6 showed the same band patterns as event \#4 (data not shown), we obtained three independent transgenic events of $M$. sinensis SNUM-045 germplasm from the transformation. When the Agrobacterium-mediated transformation efficiency was calculated as a percentage of independent transgenic events obtained from all inoculated calli (three independent transgenic events using 347 calli), a transformation efficiency of $0.86 \%$ was obtained. These results proved that we established the Agrobacterium-mediated transformation system for $M$. sinensis and successfully obtained the transgenic plants of $M$. sinensis.

\section{Production of herbicide-resistant $M$. sinensis plants}

With the established genetic transformation system of $M$. sinensis germplasm SNU-M-045, we also tried to generate herbicide-resistant $M$. sinensis plants. To this end, pCAMBIA3301 vector harboring the $B A R$ gene was introduced into $M$. sinensis and the $B A R$ gene was also used as a selectable marker. Since the minimum concentrations of phosphinotricin (PPT) that inhibit plant regeneration of non-transformed calli were shown to be $3-5 \mathrm{mg} \mathrm{L}^{-1} \mathrm{PPT}$, transgenic calli were selected with $5 \mathrm{mg} \mathrm{L}^{-1}$ PPT and PPT-resistant shoots were induced on shoot induction media containing $3 \mathrm{mg} \mathrm{L}^{-1}$ PPT. Phosphinotricin is the active component of bialaphos (phosphinotricyl-alanyl-alanine), which is a non- 


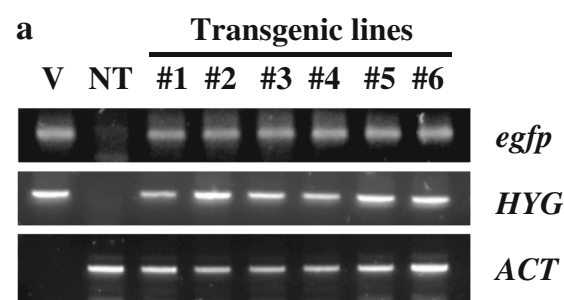

b Transgenic lines NT \#1 \#2 \#3 \#4 \#5 \#6 NT

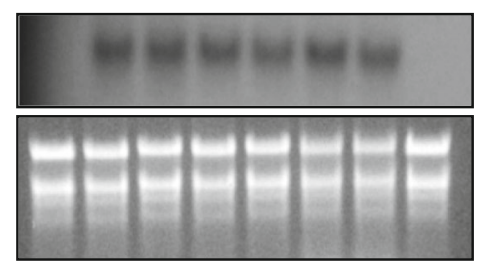

HYG

Total RNA

Fig. 5 Molecular analyses of transgenic $M$. sinensis plants. a Genomic PCR analysis of putative transgenic plants. The coding regions of egfp and $H Y G$ genes were amplified by PCR from genomic DNA. The actin gene $(A C T)$ was shown as a loading control of the genomic DNA. V, pCAMBIA1300 vector harboring egfp gene that was used for transformation; $N T$ non-transformed $M$. sinensis control plant.

selective and broad-spectrum contact herbicide also known as glufosinate (Wehrmann et al. 1996). During the selection of transgenic plants, it is notable that PPT-resistant shoots were grown slowly compared with hygromycin-resistant shoots (Supplementary Fig. 5). Thus, it took more time to obtain herbicide-resistant transgenic shoots ( $>9$ weeks) than hygromycin-resistant transgenic shoots ( $>6$ weeks). After root induction, the putative transgenic plantlets with roots were transferred to soil and grown under greenhouse conditions before herbicide resistance analysis. From this transformation, we obtained seven transgenic plants from four independent events. When the Agrobacterium-mediated transformation efficiency was calculated as a percentage of independent transgenic events obtained from all inoculated calli, the efficiency was $0.58 \%$ (four out of 687), which was lower than that from transformation using the hygromycin resistance selection $(0.86 \%)$.

Next, we performed the molecular analysis of putative transgenic plants obtained from the transformation with $B A R$. First, genomic PCR analysis was performed using $B A R$ primers to test for the presence of the transgene, and the results confirmed that all seven putative transgenic plants contained the BAR transgene (Fig. 6a). Second, the expression of the $B A R$ transgene in four independent transgenic events was confirmed by Northern blot analysis (Fig. 6b). These results confirmed that the putative transgenic plants are all real transgenic plants. Finally, herbicide resistance assays were conducted by spraying with $0.4 \%$ BASTA $^{\circledR}$, which is a commercial herbicide containing

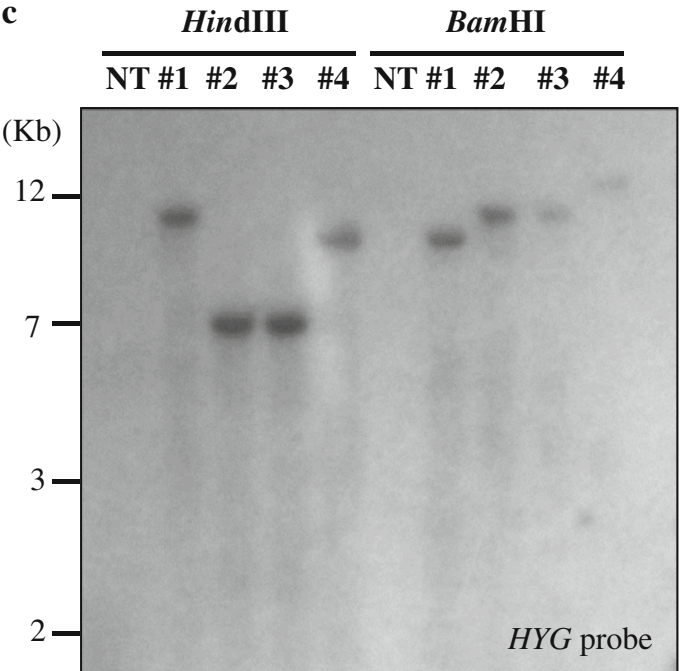

Numbers in lanes represent transgenic plants used for analysis. b Northern blot analysis. Total RNA was isolated from the leaves of transgenic plants and the $H Y G$ gene was used as a probe. Total RNA was also shown as a loading control. c DNA gel blot analysis. Genomic DNA from each transgenic plant was digested with either HindIII or BamHI, and then probed with the $H Y G$ gene

$18 \%$ glufosinate. The results showed that all the transgenic plants exhibited herbicide resistance, while control plants died within 14 days (Fig. 6c). All the transgenic plants were morphologically indistinguishable from the control plant, with the exception of herbicide resistance. Therefore, we have successfully produced herbicide-resistant $M$. sinensis plants using the transformation system established in this study. To our knowledge, this is the first report to obtain genetically engineered Miscanthus plants with herbicide resistance using an Agrobacterium-mediated transformation method.

To evaluate the Agrobacterium-mediated transformation efficiency more reliably, we performed three more transformations with hygromycin resistance selection and two more transformations with herbicide resistance selection (in total, four experiments with $H Y G$ as the selectable marker and three experiments with $B A R$ as the selectable marker). The efficiencies with the accumulated numbers of transformation were then calculated. The results showed approximately $1.06 \%$ efficiency with the hygromycin resistance selectable marker and $0.52 \%$ with the herbicide resistance selectable marker, based on the percentages of independent transgenic events obtained from all inoculated calli (Table 3). Overall, we could repeatedly obtain transgenic plants of $M$. sinensis by using the Agrobacteriummediated transformation system established in this study, suggesting that the developed transformation method can be used stably for the introduction of other useful gene(s) into M. sinensis. 
a

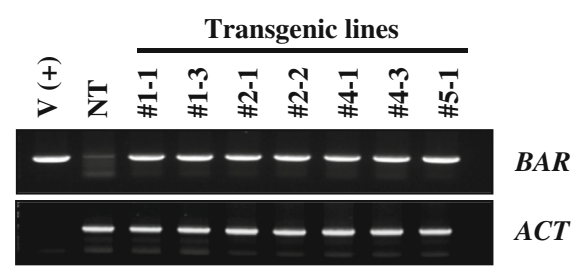

b

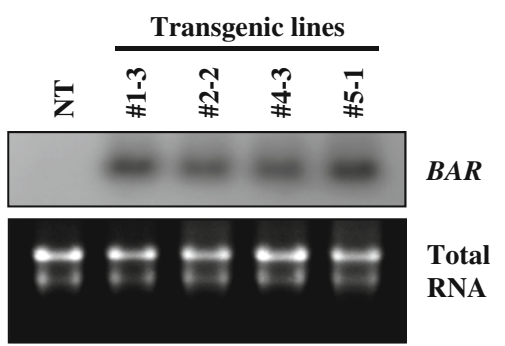

c Before herbicide treatment
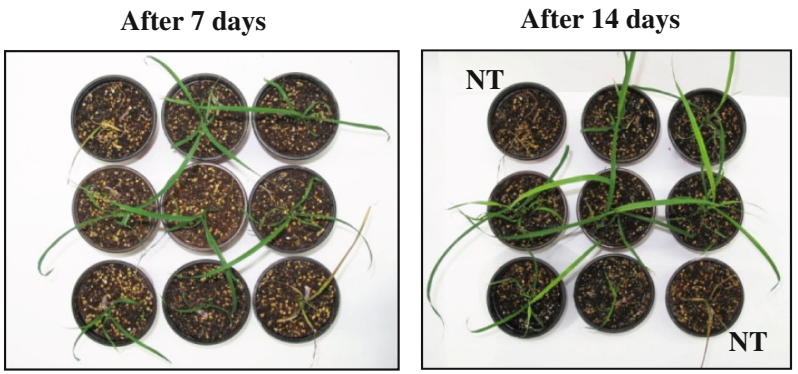

Fig. 6 Production of transgenic M. sinensis plants with herbicide resistance. a Genomic PCR analysis of putative transgenic plants. The coding region of the $B A R$ gene was amplified by PCR from genomic DNA. The actin gene $(A C T)$ was shown as a loading control. V (+), pCAMBIA3301 vector included as a positive control; NT nontransformed control plant. Numbers in lanes represent transgenic

plants used for analysis. b Northern blot analysis. Total RNA was isolated from the leaves of independent transgenic events and the $B A R$ gene was used as a probe. Total RNA was shown as a loading control. c Herbicide resistance assay. $0.4 \%$ BASTA $^{\circledR}$ was sprayed onto nontransformed control plant (NT) and transgenic plants, and the herbicide resistance of the plants was determined 7 or 14 days later

Table 3 Transformation efficiencies of Agrobacterium-mediated transformation for M. sinensis

\begin{tabular}{|c|c|c|c|c|}
\hline No. of experiments & Vector (selection marker) & $\begin{array}{l}\text { No. of inoculated } \\
\text { calli }\end{array}$ & $\begin{array}{l}\text { No. of transgenic } \\
\text { events (plants) }\end{array}$ & $\begin{array}{l}\text { Transformation } \\
\text { efficiency }(\%)^{\mathrm{b}}\end{array}$ \\
\hline 4 & $\begin{array}{l}\text { pCAMBIA1300 } \\
(H Y G)\end{array}$ & 1,316 & $14(29)$ & $1.06 \pm 0.19$ \\
\hline 3 & $\begin{array}{l}\text { pCAMBIA3301 } \\
(B A R)\end{array}$ & 1,542 & $8(36)$ & $0.52 \pm 0.32$ \\
\hline
\end{tabular}

\footnotetext{
a Transgenic events represent transformed calli which produce hygromycin- or herbicide-resistant plants

b Transformation efficiency was calculated using the number of transgenic events from all inoculated calli. The data represent the mean \pm SD of three or four independent experiments
}

\section{Discussion}

The important steps for Agrobacterium-mediated transformation of crops include the induction of regenerable embryogenic calli, DNA delivery into the embryogenic calli by the inoculation and co-cultivation of Agrobacterium cells harboring a vector with target gene(s), and the selection of transformed calli and regeneration of transgenic plants (Kim et al. 2007; Engler and Jakob 2013). Thus, the first critical step for the success of the genetic transformation might be the step to obtain embryogenic calli which has high regeneration potentials. In the case of Miscanthus species, the production of regenerable embryogenic calli has been reported from inflorescences (Głowacka et al. 2010; Kim et al. 2010) or mature seeds (Wang et al. 2011). Although the use of inflorescences was reported to be efficient for micropropagation of Miscanthus species, it might not be effective for the genetic transformation because of limited availability of the materials. Therefore, we used mature seeds-derived embryogenic calli to develop Agrobacterium-mediated transformation system for $M$. sinensis, as the embryogenic callus tissue derived from mature seeds has been successfully used for Agrobacterium-mediated transformation of several monocotyledons (Cheng et al. 2004). Our results showed that regenerable embryogenic calli were efficiently induced with the optimized CIM containing $3 \mathrm{mg} \mathrm{L}^{-1}$ 2,4-D and $25 \mathrm{mM}$ L-proline, at pH 5.7 with an induction temperature of $28{ }^{\circ} \mathrm{C}$ (Figs. 1, 2 and Supplementary Fig. 2). The preferred temperature of $28{ }^{\circ} \mathrm{C}$ for embryogenic callus induction of $M$. sinensis is consistent with the reports that incubating temperatures of $26-28{ }^{\circ} \mathrm{C}$ are suitable for 
embryogenic callus induction for warm season grasses (Smith et al. 2002; Toyama et al. 2003; Wang et al. 2011). Compared with previous reports that addition of BA showed the improved frequency of embryogenic callus induction (Petersen 1997; Wang et al. 2011), the improvement by the BA addition was not observed in our experimental conditions (Supplementary Fig. 2 and Fig. 1c). The differences in our and previous results might be due to the use of different materials (shoot apices vs. mature seeds) or the use of different concentrations of 2,4D $\left(5 \mathrm{mg} \mathrm{L}^{-1}\right.$ in the previous report vs. $3 \mathrm{mg} \mathrm{L}^{-1}$ in the present study). Rather, we found that the inclusion of $\mathrm{L}^{-}$ proline in callus induction and shoot induction media was helpful to increase the percentages of embryogenic calli and the regeneration potentials in M. sinensis (Fig. 2; Table 2). These results were consistent with previous reports that the addition of L-proline increases the induction of embryogenic calli (Holme et al. 1997; Li and Qu 2011).

More importantly, the use of $M$. sinensis germplasm seeds was critical for the success of Agrobacterium-mediated transformation. The commercially purchased seeds (i.e., Geumo seeds) were not adequate for genetic transformation, probably because they were harvested from different $M$. sinensis varieties. Thus, we planned to select germplasm seeds which have higher embryogenic callus induction and regeneration potentials than the Geumo seeds. In this study, we tested seven germplasms from Seoul National University, and selected the germplasm SNU-M-045 from Incheon in Korea for the transformation, as it showed a high ratio of embryogenic callus induction and superior regeneration potentials (Table 2 and Supplementary Fig. 3). Similarly, Wang et al. (2011) also reported the importance of genotypes in embryogenic callus induction and genetic transformation of $M$. sinensis, and used a germplasm from Tanegashima Island in Japan for the development of particle bombardment-mediated transformation system. In the present study, we could establish a stable Agrobacterium-mediated genetic transformation system for M. sinensis with the SNU-M-045 germplasm seeds (Fig. 4 and Supplementary Table 3).

For the inoculation and co-cultivation of Agrobacterium cells to deliver transgenes into embryogenic calli of $M$. sinensis, conditions with relatively high concentration of acetosyringone $(400 \mu \mathrm{M})$ and relatively long co-cultivation period (5 days) were shown to be effective (Supplementary Table 2), when compared with the conditions for other monocotyledons (Kim et al. 2007; Alves et al. 2009; Li and Qu 2011; Kim et al. 2013). As an example, $200 \mu \mathrm{M}$ acetosyringone and 3 days of co-cultivation were used in a recent report for Agrobacteriummediated transformation of reed (Phragmites communis Trinius) using mature seeds-derived embryogenic calli (Kim et al. 2013). For the selection of transformed calli and transgenic plants, we initially used hygromycin antibiotics for the selection of transgenic plants following the transformation with pCAMBIA1301 vector. Miscanthus species was known to be susceptible to many of antibiotics and herbicides including hygromycin and BASTA, but not kanamycin (Engler and Jakob 2013). The results of molecular analyses showed that all the putative transgenic plants obtained from the hygromycin resistance selection were transgenic plants with transgenes (Fig. 5). Since the transgenic plants obtained in this study contained one genomic copy of transgene with similar mRNA expression, our results reinforced that the Agrobacterium-mediated method of transformation is better than the biolistic method which frequently produces transgenic plants with multiple copies of transgene (Dai et al. 2001; Travella et al. 2005).

Using the number of independent transgenic events, approximately 1.06 or $0.52 \%$ transformation efficiency was obtained with hygromycin resistance or herbicide resistance selection, respectively (Table 3). The transformation efficiency with the herbicide resistance selection was lower than that with the hygromycin resistance selection, probably because PPT might have a negative effect on tissue growth and thus shoot development was not effective in PPT-containing media compared with hygromycin-containing media (Alves et al. 2009). Overall, the transformation efficiency of M. sinensis obtained in this study was relatively lower than that of other monocotyledonous grasses (Kim et al. 2007; Somleva et al. 2008). Therefore, further improvement of the transformation system for Miscanthus species will be necessary in the future.

For successful establishment of new Miscanthus plantations, there is a significant concern for weed control in the planting year, because young Miscanthus plants can easily be overgrown by weeds causing substantial plant loss. Thus, herbicide control during the establishment would be desirable, and herbicide-resistant Miscanthus plants can be produced by genetic engineering methods using transformation technologies. In this study, we have successfully produced herbicide-resistant $M$. sinensis plants by introducing the BAR gene (Fig. 6). Thus, the herbicideresistant $M$. sinensis plants developed in this study would provide a useful tool for controlling unwanted weeds, and allow easier maintenance of Miscanthus growth in fields, as well as reduce the number and amount of pollution-generating agrochemicals required. Moreover, the developed Agrobacterium-mediated transformation system of M. sinensis will help to introduce useful traits from a broad range of sources into the Miscanthus plants and also to develop the genetic transformation system for other Miscanthus species, which may provide a method to produce new bioenergy crop varieties with high value in the future.

Acknowledgments We thank the Kumho Life Science Laboratory in Chonnam National University for providing plant growth facilities. 
This work was supported mainly by Technology Development Program for Agriculture and Forestry, Ministry for Agriculture, Forestry and Fisheries, Republic of Korea (Grant No. 309017-5) and partly by Next-Generation BioGreen 21 Program, Rural Development Administration, Republic of Korea (Grant No. PJ00949101).

Open Access This article is distributed under the terms of the Creative Commons Attribution License which permits any use, distribution, and reproduction in any medium, provided the original author(s) and the source are credited.

\section{References}

Alves SC, Worland B, Thole V, Snape JW, Bevan MW, Vain P (2009) A protocol for Agrobacterium-mediated transformation of Brachypodium distachyon community standard line $\mathrm{Bd} 21$. Nat Protoc 4:638-649

Balat M (2011) Production of bioethanol from lignocellulosic materials via the biochemical pathway: a review. Energy Convers Manag 52:858-875

Carroll A, Somerville C (2009) Cellulosic biofuels. Annu Rev Plant Biol 60:165-182

Chen H, Nelson RS, Sherwood JL (1994) Enhanced recovery of transformants of Agrobacterium tumefaciens after freeze-thaw transformation and drug selection. Biotechniques 16:664-670

Cheng M, Lowe BA, Spencer TM, Ye XD, Armstrong CL (2004) Factors influencing Agrobacterium-mediated transformation of monocotyledonous species. In Vitro Cell Dev Biol 40:31-45

Cho KC, Han YJ, Kim SJ, Lee SS, Hwang OJ, Song PS, Kim YS, Kim JI (2011) Resistance to Rhizoctonia solani AG-2-2 (IIIB) in creeping bentgrass plants transformed with pepper esterase gene PepEST. Plant Pathol 60:631-639

Christian DG, Yates NE, Riche AB (2005) Establishing Miscanthus sinensis from seed using conventional sowing methods. Ind Crops Prod 21:109-111

Dai SH, Zheng P, Marmey P, Zhang SP, Tian WZ, Chen SY, Beachy RN, Fauquet C (2001) Comparative analysis of transgenic rice plants obtained by Agrobacterium-mediated transformation and particle bombardment. Mol Breeding 7:25-33

Engler D, Jakob K (2013) Genetic engineering of Miscanthus. In: Paterson AH (ed) Genomics of the Saccharinae. Springer, New York, pp 255-301

Głowacka K, Jeżowski S (2009) Genetic and nongenetic factors influencing callus induction in Miscanthus sinensis (Anderss.) anther cultures. J Appl Genet 50:341-345

Głowacka K, Jeżowski S, Kaczmarek Z (2010) The effects of genotype, inflorescence developmental stage and induction medium on callus induction and plant regeneration in two Miscanthus species. Plant Cell Tissue Organ Cult 102:79-86

Gomez LD, Steele-King CG, McQueen-Mason SJ (2008) Sustainable liquid biofuels from biomass: the writing's on the walls. New Phytol 178:473-485

Han YJ, Kim YM, Lee JY, Kim SJ, Cho KC, Chandrasekhar T, Song PS, Woo YM, Kim JI (2009) Production of purple-colored creeping bentgrass using maize transcription factor genes $P l$ and Lc through Agrobacterium-mediated transformation. Plant Cell Rep 28:397-406

Han YJ, Cho KC, Hwang OJ, Choi YS, Shin AY, Hwang I, Kim JI (2012) Overexpression of an Arabidopsis $\beta$-glucosidase gene enhances drought resistance with dwarf phenotype in creeping bentgrass. Plant Cell Rep 31:1677-1686
Heaton EA, Dohleman FG, Long SP (2008) Meeting US biofuel goals with less land: the potential of Miscanthus. Glob Chang Biol 14:2000-2014

Heaton EA, Dohleman FG, Miguez AF, Juvik JA, Lozovaya V, Widholm J, Zabotina OA, Mcisaac GF, David MB, Voigt TB, Boersma NN, Long SP (2010) Miscanthus: a promising biomass crop. Adv Bot Res 56:75-137

Holme IB, Krogstrup P, Hansen J (1997) Embryogenic callus formation, growth and regeneration in callus and suspension cultures of Miscanthus $\times$ ogiformis Honda Giganteus' as affected by proline. Plant Cell Tissue Organ Cult 50:203-210

Jakob K, Zhou FS, Paterson A (2009) Genetic improvement of C4 grasses as cellulosic biofuel feedstocks. In Vitro Cell Dev Biol 45:291-305

Kim SJ, Lee JY, Kim YM, Yang SS, Hwang OJ, Hong NJ, Kim KM, Lee HY, Song PS, Kim JI (2007) Agrobacterium-mediated highefficiency transformation of creeping bentgrass with herbicide resistance. J Plant Biol 50:577-585

Kim J, Kim Y, Yeom M, Kim JH, Nam HG (2008) FIONA1 is essential for regulating period length in the Arabidopsis circadian clock. Plant Cell 20:307-319

Kim HS, Zhang G, Juvik JA, Widholm JM (2010) Miscanthus $\times$ giganteus plant regeneration: effect of callus types, ages and culture methods on regeneration competence. GCB Bioenergy 2:192-200

Kim YG, Sharmin SA, Alam I, Kim KH, Kwon SY, Sohn JH, Kim SH, Liu G, Lee BH (2013) Agrobacterium-mediated transformation of reed (Phragmites communis Trinius) using mature seed-derived calli. GCB Bioenergy 5:73-80

Lewandowski I, Clifton-Brown JC, Scurlock JMO, Huisman W (2000) Miscanthus: European experience with a novel energy crop. Biomass Bioenergy 19:209-227

Lewandowski I, Scurlock JMO, Lindvall E, Christou M (2003) The development and current status of perennial rhizomatous grasses as energy crops in the US and Europe. Biomass Bioenergy 25:335-361

Li RY, Qu RD (2011) High throughput Agrobacterium-mediated switchgrass transformation. Biomass Bioenergy 35:1046-1054

Naik SN, Goud VV, Rout PK, Dalai AK (2010) Production of first and second generation biofuels: a comprehensive review. Renew Sustain Energy Rev 14:578-597

Park CH, Kim YG, Kim KH, Alam I, Lee HJ, Sharmin SA, Lee KW, Lee BH (2009) Effect of plant growth regulators on callus induction and plant regeneration from mature seed culture of Miscanthus sinensis. J Korean Soc Grassl Forage Sci 29:291-298

Petersen KK (1997) Callus induction and plant regeneration in Miscanthus $\times$ ogiformis Honda 'Giganteus' as influenced by benzyladenine. Plant Cell Tissue Organ Cult 49:137-140

Płażek AD, Dubert F (2010) Improvement of medium for Miscanthus $\times$ giganteus callus induction and plant regeneration. Acta Biol Crac 52:105-110

Smith RL, Grando MF, Li YY, Seib JC, Shatters RG (2002) Transformation of bahiagrass (Paspalum notatum Flugge). Plant Cell Rep 20:1017-1021

Somleva MN, Snell KD, Beaulieu JJ, Peoples OP, Garrison BR, Patterson NA (2008) Production of polyhydroxybutyrate in switchgrass, a value-added co-product in an important lignocellulosic biomass crop. Plant Biotechnol J 6:663-678

Takahashi W, Takamizo T (2012) Molecular breeding of grasses by transgenic approaches for biofuel production. In: Çiftçi YO (ed) Transgenic plants-advances and limitations. InTech, Rijeka, pp 91-116

Toyama K, Bae CH, Kang JG, Lim YP, Adachi T, Riu KZ, Song PS, Lee HY (2003) Production of herbicide-tolerant zoysiagrass by Agrobacterium-mediated transformation. Mol Cells 16:19-27 
Travella S, Ross SM, Harden J, Everett C, Snape JW, Harwood WA (2005) A comparison of transgenic barley lines produced particle bombardment and Agrobacterium-mediated techniques. Plant Cell Rep 23:780-789

van der Weijde T, Alvim Kamei CL, Torres AF, Vermerris W, Dolstra O, Visser RG, Trindade LM (2013) The potential of C4 grasses for cellulosic biofuel production. FPLS 4:107

Wang X, Yamada T, Kong FJ, Abe Y, Hoshino Y, Sato H, Takamizo T, Kanazawa A, Yamada T (2011) Establishment of an efficient in vitro culture and particle bombardment-mediated transformation systems in Miscanthus sinensis Anderss., a potential bioenergy crop. GCB Bioenergy 3:322-332

Wehrmann A, Van Vliet A, Opsomer C, Botterman J, Schulz A (1996) The similarities of bar and pat gene products make them equally applicable for plant engineers. Nat Biotechnol 14: $1274-1278$
Yuan JS, Tiller KH, Al-Ahmad H, Stewart NR, Stewart CN Jr (2008) Plants to power: bioenergy to fuel the future. Trends Plant Sci 13:421-429

Zhang QX, Sun Y, Hu HK, Chen B, Hong CT, Guo HP, Pan YH, Zheng BS (2012) Micropropagation and plant regeneration from embryogenic callus of Miscanthus sinensis. In Vitro Cell Dev Biol 48:50-57

Zhu XG, Long SP, Ort DR (2008) What is the maximum efficiency with which photosynthesis can convert solar energy into biomass? Curr Opin Biotechnol 19:153-159

Zub HW, Brancourt-Hulmel M (2010) Agronomic and physiological performances of different species of Miscanthus, a major energy crop. A review. Agron Sustain Dev 30:201-214 